\title{
The Association of Grades of Photoreceptor Inner Segment-Ellipsoid Band Disruption with Severity of Retinopathy in Type 2 Diabetes Mellitus
}

Sharma $\mathrm{SR}^{1}$, Saxena $\mathrm{S}^{* 1}$, Mishra $\mathrm{N}^{1}$, Akduman $\mathrm{L}^{2}$ and Meyer $\mathrm{CH}^{3}$

${ }^{1}$ Retina Service, Department of Ophthalmology, King George's Medical University, Lucknow, India

${ }^{2}$ Department of Ophthalmology, Saint Louis University Eye Institute, St. Louis University, St. Louis, U.S.A

${ }^{3}$ Department of Ophthalmology, Pallas Klinik, Olten, Switzerland

${ }^{*}$ Corresponding author: Saxena S, Retina Service, Department of Ophthalmology, King George's Medical University, Lucknow, India, E-mail: sandeepsaxena2020@yahoo.com

Citation: Sharma SR, Saxena S, Mishra N, Akduman L, Meyer CH (2014) The Association of Grades of Photoreceptor Inner Segment-Ellipsoid Band Disruption with Severity of Retinopathy in Type 2 Diabetes Mellitus. J Case Rep Stud 2(5): 502. doi: 10.15744/2348-9820.2.202

Received Date: May 20, 2014 Accepted Date: October 03, 2014 Published Date: October 07, 2014

\begin{abstract}
A prospective case-control study was undertaken to evaluate the association of inner segment-ellipsoid (ISel) band disruption with severity of diabetic retinopathy on spectral-domain optical coherence tomography. ISel disruption was graded as - grade 0: intact ISel; grade 1: focal disruption (subfoveal ISel disruption) and grade 2: global disruption (ISel disruption involving macular cube). Increased severity of diabetic retinopathy was found to be associated with increase in disruption of ISel $(\mathrm{r}=0.49, \mathrm{p}<0.001)$. 'Global' disruption of ISel in proliferative diabetic retinopathy (PDR) $(n=40)$ was significantly higher as compared non proliferative diabetic retinopathy (NPDR) $(n=40)$ (Intact/Focal/Global: 5/25/10 (NPDR) vs. 0/11/29 (PDR), $\left.\chi^{2}=19.70 ; p<0.0001\right)$. Decrease in visual acuity was found to be significantly associated with increased disruption of ISel and severity of retinopathy.
\end{abstract}

\section{Introduction}

Diabetic retinopathy is an important cause of preventable blindness [1]. It a major microvascular complication in type 2 diabetes mellitus [2]. It leads to several structural changes in retina which correlates with severity of retinopathy [3].

Optical coherence tomography provides information akin to live in-vivo histology of the retina [4]. Recently Spaide et al and Curcio et al speculated that the outer highly reflective band next to retinal pigment epithelium was located at the ellipsoid in the inner segments which correlated between the retinal microstructure on the SD-OCT images and the histologic findings [5,6]. Thus it is more appropriate to consider the previously termed inner segment-outer segment (IS-OS) junction to be photoreceptor inner segment ellipsoid band (ISel). Photoreceptor ISel has been found to be visible on optical coherence tomography (OCT) due to its biological activity rather than the structure in an animal model [7]. Our recent study highlighted that an increase in serum vascular endothelial growth factor and intercellular adhesion molecule-1levels is associated with an increase in the severity of diabetic retinopathy and the grade of subfoveal external limiting membrane (ELM) and ISel disruption [8].

In the present study we examined, in patients of type 2 diabetes mellitus, the association of 'focal' and 'global' grades of ISel disruption with the severity of diabetic retinopathy and change in visual acuity, using SD-OCT.

\section{Methods}

Our study had institutional review board clearance and was performed in accordance to the tenets of the Helsinki declaration. A written informed voluntary consent was taken from all the study subjects. The study was a tertiary care center based prospective cross sectional study of 120 eyes of 120 consecutive patients with type 2 diabetes mellitus. Patients with ocular diseases which could affect the retinal pathology (for example hypertensive retinopathy, age related macular degeneration, polypoidal choroidal vasculopathy and central serous chorioretinopathy), any previous surgical or laser interventions, fluorescein angiography suggestive of ischemic maculopathy, vitreous hemorrhage, tractional retinal detachment and patients with signal strength 5 or below on SD-OCT examination (due to media opacity), were excluded from the study. The best-corrected visual acuity was recorded on $\log$ MAR scale. Information regarding patient's age, gender, disease duration, status of retinopathy and glycemic control were recorded. All the study subjects underwent detailed fundus evaluation using stereoscopic slit lamp biomicroscopy and indirect ophthalmoscopy. Digital fundus photography and flourescein angiography were done using Zeiss fundus camera FF 450 Plus with pixel width of 0.0054 and image size $2588 \times 1958$. Fluorescein angiography was performed in cases with diabetic retinopathy. Cases were divided into three groups: patients of diabetes without retinopathy $(n=40)$, non- proliferative diabetic retinopathy $(n=40)$, 
and proliferative diabetic retinopathy $(n=40)$ according to the ETDRS classification [9]. Diabetic macular edema was defined as per ETDRS classification and based on SD-OCT [10,11]. One eye per case was included. Eye with more severe form of diabetic retinopathy was included. Right eye of the cases without retinopathy was included.

Subsequently, all the study subjects were evaluated using SD-OCT [Cirrus High Definition OCT (Carl Zeiss Meditec Inc., CA, U.S.A]. Every study subject underwent macular thickness analysis using macular cube 512x128 feature. Central subfoveal thickness $(\mu \mathrm{m})$, cube average thickness $(\mu \mathrm{m})$ and cube volume $\left(\mathrm{mm}^{3}\right)$ were noted. Inner segment-ellipsoid band was studied using horizontal and vertical SD-OCT scans passing through the fovea. The integrity of this layer was evaluated by two experienced observers masked to the status of diabetic retinopathy. ISel disruption was graded into three categories- grade 0: intact ISel; grade 1: focal disruption (subfoveal ISel disruption) and grade 2: global disruption (ISel disruption involving macular cube) (Figure 1).

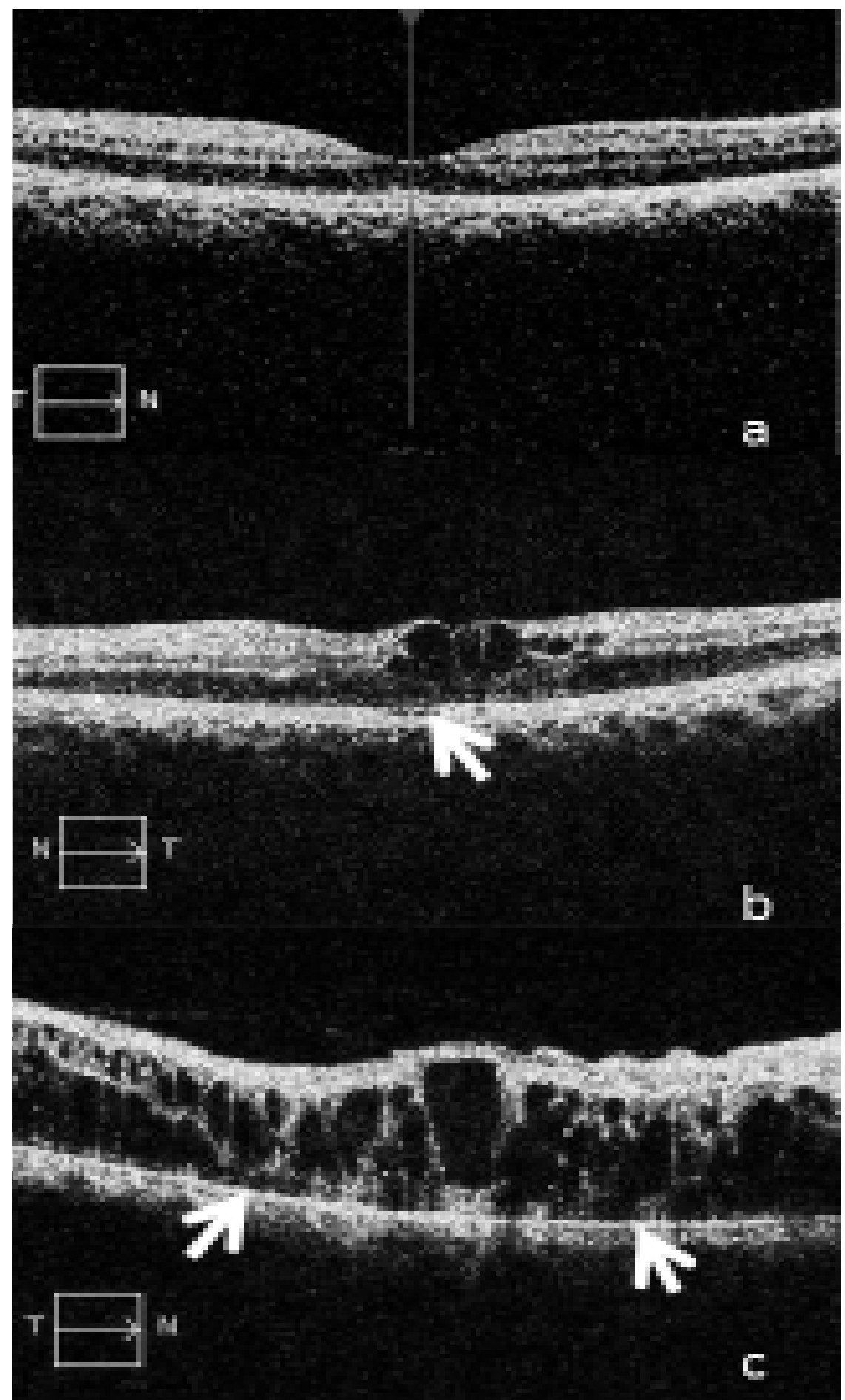

Figure 1: Spectral domain optical coherence tomography images through the fovea showing grades of inner segment-ellipsoid band (ISel) disruption in patients with diabetic retinopathy. a) Grade 0: intact ISel; b) Grade 1: Focal disruption (subfoveal ISel disruption); c) Grade 2: Global disruption (ISel) disruption involving macular cube. White arrow denotes the area of ISel disruption. 
Data is presented as mean \pm standard error (SE). The continuous variables (age, macular thickness and cube thickness) of the study groups - NPDR and PDR were compared by one factor analysis of variance (ANOVA) and the significance of mean difference between the groups was done by Newman-Keuls post hoc test. The categorical variables (sex and disruption of ISel were compared by chi-square $\left(\chi^{2}\right)$ test. The logMAR vision score of two groups (NPDR and PDR) was compared by independent Student's t test and non-parametric Mann-Whitney U test. Pearson correlation analysis was used to assess association between the variables and intraclass correlation. Interobserver correlation was computed using analysis of variance. A p $<0.05$ was considered statistically significant. All analyses were performed on STATISTICA (window version 6.0) software.

\section{Results}

One hundred and twenty eyes of 120 consecutive study subjects were included in the study. There were sixty eight males and fifty two females. The mean age of patients was $52.4 \pm 4.36$ years, $53.5 \pm 3.68$ years and $56.2 \pm 4.12$ years in patients of diabetes without retinopathy, NPDR and PDR groups respectively. No statistical difference was found among the age and sex of the three groups ( $\mathrm{p}>0.05)$. Mean $\log$ MAR visual acuity was 0.15 in patients with no diabetic retinopathy, 0.75 in NPDR and 1.3 in PDR. The mean macular thickness was $242.53 \pm 4.09 \mu \mathrm{m}$ in eyes without retinopathy, $321.45 \pm 24.25 \mu \mathrm{m}$ in eyes with NPDR and $319.03 \pm 18.64$ $\mu \mathrm{m}$ in eyes with PDR. Cube thickness was $253.83 \pm 1.27 \mu \mathrm{m}$ in eyes without retinopathy, $334.9 \pm 10.47 \mu \mathrm{m}$ in NPDR and $335.45 \pm$ $7.46 \mu \mathrm{m}$ in PDR groups. Cube volume was $11.28 \pm 1.7 \mathrm{~mm}^{3}$ in eyes without retinopathy, $12.29 \pm 2.1 \mathrm{~mm}^{3}$ in NPDR and $12.17 \pm 2.8$ $\mathrm{mm}^{3}$ in PDR groups. In the NPDR group, 37/40 eyes had diabetic macular edema. All eyes (40/40) in the PDR group had diabetic macular edema.

Interobserver correlation for analysis of the ISel on SD-OCT scan was computed as 0.72 . An intraclass correlation coefficient for the grading of ISel disruption was 0.93 (95\% confidence interval, 0.93 to 0.96). Eyes without diabetic retinopathy had normal ISel. Focal ISel disruption was observed in 25 eyes (62.5\%) with NPDR and 11 (27.5\%) eyes with PDR. Global ISel disruption was observed in 10 eyes (25\%) with NPDR and 29 eyes (72.5\%) with PDR. The $\chi 2$ test revealed that focal disruption of ISel in NPDR group was significantly higher as compared to PDR group. The $\chi^{2}$ test revealed that global disruption of ISel in PDR group was significantly higher as compared to NPDR group (Intact/Focal/Global: 5/25/10 (NPDR) vs. 0/11/29 (PDR), $\chi^{2}=19.70 ; p<0.0001$ ).

Table 1 shows the correlation of the study variables. Our analysis revealed no significant association of central subfoveal macular thickness, cube average thickness and cube volume with severity of retinopathy and visual acuity. Increased severity of diabetic retinopathy was found to be associated with increase in disruption of ISel from 'focal' to 'global' grade $(\mathrm{r}=0.49, \mathrm{p}<0.001)$. Decrease in visual acuity was found to be associated with increase in grade of disruption of ISel $(y=0.5542 x+0.2315 ; r=0.67$, $\mathrm{p}<0.001)$. We also observed that there was marked decrease in visual acuity with global disruption as compared to the focal disruption (Figure 2).

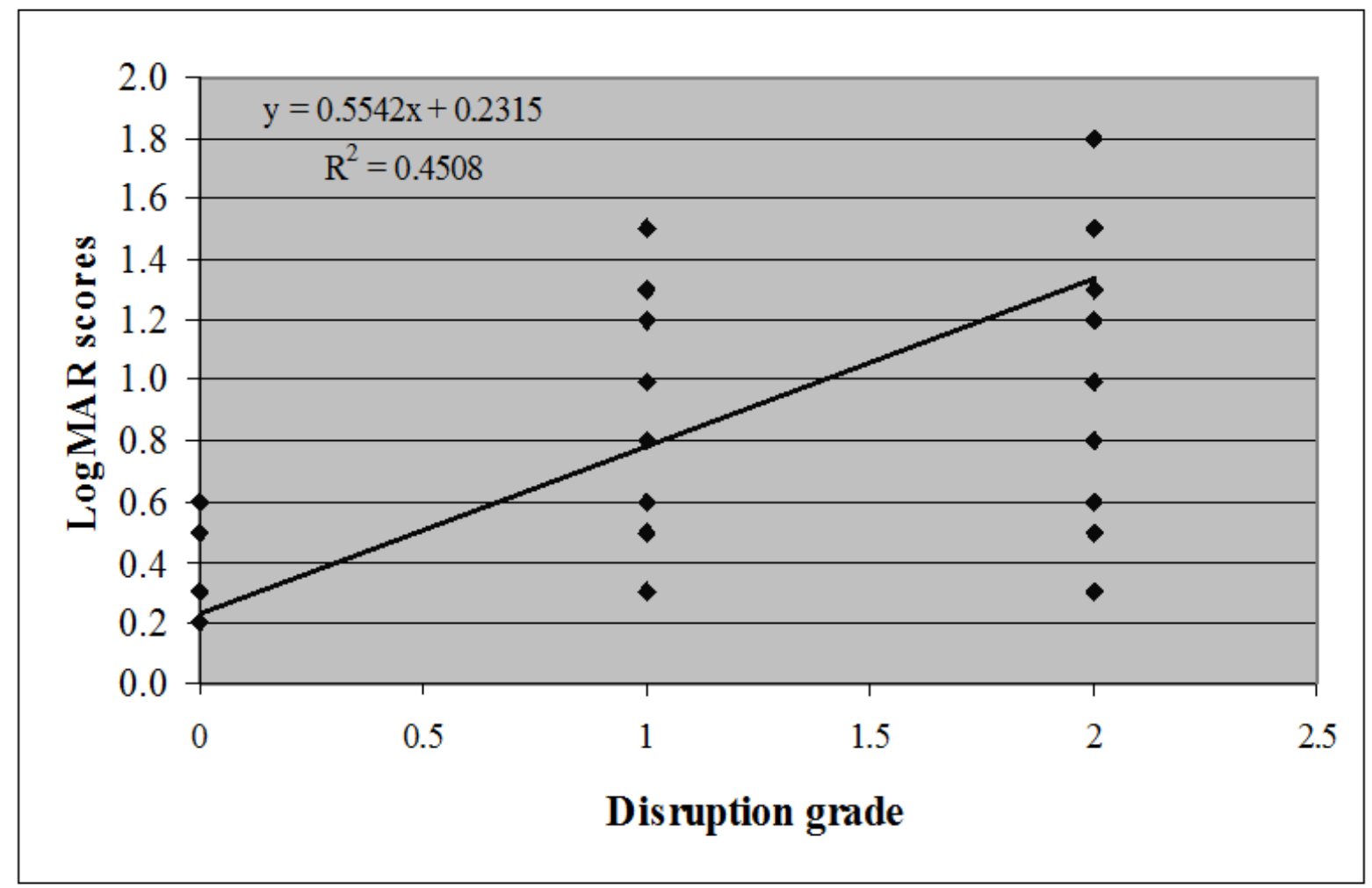

Figure 2: Relation of visual acuity with disruption of inner segment ellipsoid band (ISel) - Intact (0), Focal (1) and Global (2) is shown above, reveals that as the disruption of ISel increases there is decrease in visual acuity $(\mathrm{p}<0.001)$. 


\begin{tabular}{|c|c|c|c|c|c|}
\hline Variables & $\begin{array}{l}\text { Level of } \\
\text { retinopathy }\end{array}$ & $\log$ MAR scale & $\begin{array}{l}\text { ISel disrup- } \\
\text { tion }\end{array}$ & $\begin{array}{c}\text { Cube } \\
\text { average } \\
\text { thickness }\end{array}$ & $\begin{array}{c}\text { Central } \\
\text { subfovealmacular } \\
\text { thickness }\end{array}$ \\
\hline Level of retinopathy & 1.00 & & & & \\
\hline LogMAR scale & $0.54^{* * *}$ & 1.00 & & & \\
\hline ISel disruption & $0.49^{* * *}$ & $0.67^{* * *}$ & 1.00 & & \\
\hline $\begin{array}{l}\text { Cube average } \\
\text { thickness }\end{array}$ & $0.00^{\mathrm{ns}}$ & $0.19^{\text {ns }}$ & $0.28^{*}$ & 1.00 & \\
\hline $\begin{array}{l}\text { Central subfoveal macu- } \\
\text { lar thickness }\end{array}$ & $-0.01^{\mathrm{ns}}$ & $0.12^{\mathrm{ns}}$ & $0.18^{\mathrm{ns}}$ & $0.61^{* * *}$ & 1.00 \\
\hline
\end{tabular}

ISel - inner segment ellipsoid band

$\mathrm{ns}=\mathrm{p}>0.05,{ }^{*}=\mathrm{p}<0.05,{ }^{* *}=\mathrm{p}<0.01,{ }^{* * *}=\mathrm{p}<0.001$

Table 1: Inter-correlation among variables of non-proliferative diabetic retinopathy (NPDR) and proliferative diabetic retinopathy (PDR) groups $(\mathrm{n}=80)$.

\section{Discussion}

The present study evaluated the association between the grade of ISel disruption and change in visual acuity with severity of diabetic retinopathy. Several recent studies have highlighted the value of ISel integrity in various retinal diseases and found that its disruption correlated with poor visual acuity [12-16].

Photoreceptor dysfunction may be a significant predictor of visual acuity in patients with diabetic retinopathy [17,18]. The superior delineation of the photoreceptor ISel on SD-OCT images encouraged us to evaluate its structural integrity in vivo. Sandberg et al used ISel integrity to predict patients who were more likely to lose visual acuity as retinal thickness declined in retinitis pigmentosa [15]. Disruption of the ISel at the fovea was reported to be associated with a poor visual prognosis in resolved macular edema associated with branch retinal vein occlusion [12]. Many cross-sectional or longitudinal studies have shown the clinical relevance of the ISel in diabetic macular edema [19-25].

Maheshwary et al graded ISel disruption from grade 0-2. Grade 0: intact ISel, Grade 1: focal ISel disruption of 200 microns or less, and Grade 2: ISel disruption more than 200 microns. Grades from each patient's horizontal and vertical scan were added to yield a global disruption scale [25]. They demonstrated percentage disruption of photoreceptor ISel as an important predictor of visual acuity among diabetic macular edema patients. The transverse length of the disrupted or absent ISel has been related to visual impairment $[24,26]$.

In the present study no significant association of central subfoveal macular thickness, cube average thickness and cube volume with severity of retinopathy and visual acuity was observed. This is in agreement with earlier findings of Browning et al [27]. Recently, taking ELM into consideration, we highlighted that the grade of subfoveal ELM and ISel disruption was associated with an increase in severity of diabetic retinopathy and decrease in visual acuity. In the present study, a simplified, comprehensive and physician friendly approach of grading ISel disruption was developed. ISel could be graded quickly on horizontal and vertical scans as 'focal' and 'global' and showed excellent reproducibility. ISel disruption was found to be significantly associated with the severity of retinopathy. 'Global' ISel disruption was associated with marked increase in severity and decrease in visual acuity of as compared to 'focal' disruption.

\section{Conclusion}

SD-OCT based grading of ISel disruption into 'focal' and 'global' scales reflect upon the structural and functional alterations associated with the disease progression. Appreciation of the grade of ISel disruption will improve our ability to elucidate the dynamic relationship between the structural alterations in retina and vision.

\section{References}

1. Tomoaki Murakami, Nagahisa Yoshimura (2013) Structural Changes in Individual Retinal Layers in Diabetic Macular Edema. J Diab Res 920713.

2. Chowdhury TA, Hopkins D, Dodson PM, Vafidis GC (2002) The role of serum lipids in exudative diabetic maculopathy: is there a place for lipid lowering therapy? Eye (Lond) 16: 689-93.

3. King H, Aurbert RE, Herman WH (1998) Global burden of diabetes.1995-2025: prevalence, numerical estimates and projections. Diabetes care 21: 1414-31.

4. Saxena S, Singh K (2009) Three-dimensional retinal imaging in spectral domain optical coherence tomography. Emerging technologies in retinal diseases. Jaypee medical publishers, New Delhi 67-122.

5. Curcio CA, Messinger JD, Sloan KR, Mitra A, McGwin G, et al. (2011) Human chorioretinal layer thicknesses measured in macula-wide, high-resolution histologic sections. Invest Ophthal Vis Sci 52: 3943-54. 
6. Lu RW, Curcio CA, Zhang Y, Zhang QX, Pittler SJ, et al. (2012) Investigation of the hyper-reflective inner/ outer segment band in optical coherence tomography of living frog retina. J Biomed Opt 17: 060504.

7.Yamauchi Y, Yagi H, Usui Y, Kimura K, Agawa T, et al. (2011) Biological activity is the likely origin of the intersection between the photoreceptor inner and outer segments of the rat retina as determined by optical coherence tomography. Clin Ophthal 5: 1649-53.

8. Jain A, Saxena S, Khanna VK, Shukla RK, Meyer CH (2013) Status of serum VEGF and ICAM-1 and its association with external limiting membrane and inner segment-outer segment junction disruption in type 2 diabetes mellitus. Mol Vis 19: 1760-8.

9. ETDRS Research Group (1984) Grading Diabetic Retinopathy from Stereoscopic Color Fundus photograph: ETDRS report number 10. Ophthalmology 91: 1464-74.

10. Gangnon RE, Davis MD, Hubbard LD, Aiello LM, Chew EY, et al. (2008) A severity scale for diabetic macular edema developed from ETDRS data. Invest Ophthal Vis Sci 49: 5041-7.

11. Virgili G, Menchini F, Murro V, Peluso E, Rosa F, et al. (2011) Optical coherence tomography (OCT) for detection of macular oedema in patients with diabetic retinopathy. Cochrane Database Syst Rev 6: CD008081.

12. Murakami T, Tsujikawa A, Ohta M, Miyamoto K, Kita M, et al. (2007) Photoreceptor status after resolved macular edema in branch retinal vein occlusion treated with tissue plasminogen activator. Am J Ophthal 143: 171-3.

13. Eandi CM, Chung JE, Cardillo-Piccolino F, Spaide RF (2005) Optical coherence tomography in unilateral resolved central serous chorioretinopathy. Retina 25: 417-21.

14. Piccolino FC, de la Longrais RR, Ravera G, Eandi CM, Ventre L, et al. (2005) The foveal photoreceptor layer and visual acuity loss in central serous chorioretinopathy. Am J Ophthal 139: 87-99.

15. Sandberg MA, Brockhurst RJ, Gaudio AR, Berson EL (2005) The association between visual acuity and central retinal thickness in retinitis pigmentosa. Invest Ophthal Vis Sci 46: 3349-54.

16. Schocket LS, Witkin AJ, Fujimoto JG, Ko TH, Schuman JS, et al. (2006) Ultrahigh-resolution optical coherence tomography in patients with decreased visual acuity after retinal detachment repair. Ophthal 113: 666-72.

17. Shah SP, Patel M, Thomas D, Aldington S, Laidlaw DA (2006) Factors predicting outcome of vitrectomy for diabetic macular oedema: results of a prospective study. Br J Ophthal 90: 33-6.

18. Otani T, Kishi S (2002) A controlled study of vitrectomy for diabetic macular edema. Am J Ophthal 134: 214-9.

19. Querques G, Bux AV, Martinelli D, Iaculli C, Noci ND (2009) Intravitreal pegaptanib sodium (Macugen) for diabetic macular oedema. Acta Ophthalmologica 87: $623-30$.

20. Sakamoto A, Nishijima K, Kita M, Oh H, Tsujikawa A, et al. (2009) Association between foveal photoreceptor status and visual acuity after resolution of diabetic macular edema by pars plana vitrectomy. Graefe's Arch Clin Exp Ophthal 247: 1325-30.

21. Alasil T, Keane PA, Updike JF, Dustin L, Ouyang Y, et al. (2010) Relationship between optical coherence tomography retinal parameters and visual acuity in diabetic macular edema. Ophthal 117: 2379-86.

22. Forooghian F, Stetson PF, Meyer SA, Chew EY, Wong WT, et al. (2010) Relationship between photoreceptor outer segment length and visual acuity in diabetic macular edema. Retina 30: 63-70.

23. Otani T, Yamaguchi Y, Kishi S (2010) Correlation between visual acuity and foveal microstructural changes in diabetic macular edema. Retina 30: 774-80.

24. Yanyali A, Bozkurt KT, Macin A, Horozoglu F, Nohutcu AF (2011) Quantitative assessment of photoreceptor layer in eyes with resolved edema after pars plana vitrectomy with internal limiting membrane removal for diabetic macular edema. Ophthalmologica 226: 57-63.

25. Shin HJ, Lee SH, Chung H, Kim HC (2012) Association between photoreceptor integrity and visual outcome in diabetic macular edema. Graefes Arch Clin Exp Ophthal 250: 61-70.

26. Maheshwary AS, Oster SF, Yuson RM, Cheng L, Mojana F (2010) The association between percent disruption of the photoreceptor inner segment-outer segment junction and visual acuity in diabetic macular edema. Am J Ophthal 150: 63-67.

27. Diabetic Retinopathy Clinical Research Network, Browning DJ, Glassman AR, Aiello LP, Beck RW (2007) Relationship between optical coherence tomographymeasured central retinal thickness and visual acuity in diabetic macular edema. Ophthal 114: 525-36.

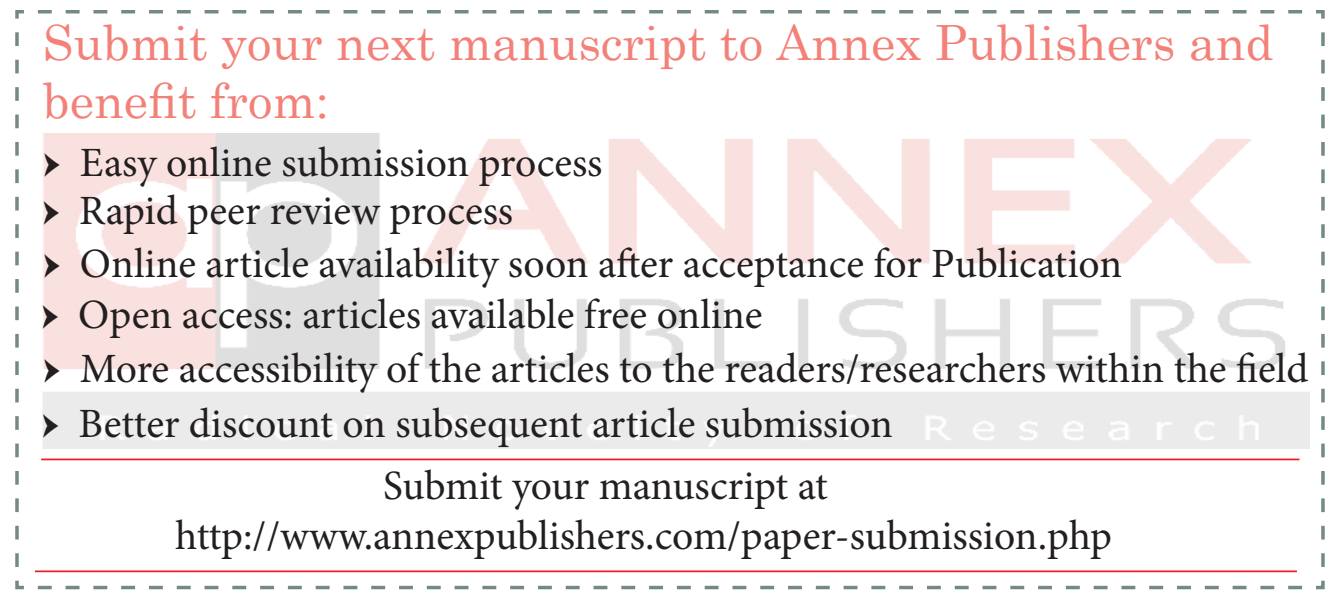

